10. Klein AH, Foley B, Kenny FM, Fisher DA 1979 Thyroid hormone and thyrotropin responses to parturition in premature infants with and without the respiratory distress syndrome. Pediatrics 63:380

11. Larsen PR 1973 Immunoassay of thyroxine in unextracted human sera. J Clin Endocrinol Metab 37:177

12. Morrison DF 1967 Multivariate Statistical Methods. McGraw Hill Book Com- pany, Inc, New York

13. Patel YC, Burger HG, Hudson B 1971 Radioimmunoassay of serum thyrotropin: sensitivity and specificity. J Clin Endocrinol Metab 33:768

14. Redding RA, Pereira C 1974 Thyroid function in respiratory distress syndrome of the newborn. Pediatrics 54:423

\title{
Respiratory Metabolism in Preterm Infants: the Measurement of Oxygen Consumpton during Prolonged Periods
}

\author{
Y. M. ABDULRAZZAQ AND O. G. BROOKE \\ Department of Child Health, St George's Hospital Medical School, Cranmer Terrace, London, \\ SW17 ORE, United Kingdom
}

\begin{abstract}
Summary
We have developed a method for measuring oxygen consumption $\left(\dot{\mathrm{V}}_{2}\right)$ in preterm infants in their normal incubator environment over prolonged periods. The results of measurements made over $\mathbf{2 4} \mathrm{h}$ in 18 infants are presented. In normally grown infants, the mean $\dot{\mathrm{V}}_{\mathrm{O}_{2}}$ was $9.66 \pm 1.25$ liters $/ \mathrm{kg} \cdot 24 \mathrm{~h}$ (SD) $(6.71 \pm 0.87$ $\mathrm{ml} / \mathrm{kg} \cdot \mathrm{min})$, and in small for gestation infants it was $10.09 \pm$ 1.21 liters $/ \mathrm{kg} \cdot 24 \mathrm{~h}(7.00 \pm 0.84 \mathrm{ml} / \mathrm{kg} \cdot \mathrm{min})$. During the $24-\mathrm{h}$ measurements, the highest mean $\dot{\mathrm{V}}_{2}$ during 3 consecutive $h$ was $7.75 \pm 0.89 \mathrm{ml} / \mathrm{kg} \bullet \mathrm{min}$ and the lowest was $5.95 \pm 0.92 \mathrm{ml} /$ $\mathrm{kg} \bullet \mathrm{min}$. The difference between the highest and the lowest values was significant $(p<0.001)$. There is room for considerable error if short term measurements are assumed to represent values over a whole day. "Short" measurements should be made over at least $6 \mathrm{~h}$.
\end{abstract}

\section{Abbreviations}

$\dot{\mathrm{V}}_{2}$, oxygen consumption rate

MR, metabolic rate

ME, metabolizable energy intake

$R Q$, respiratory quotient

The measurement of oxygen consumption in neonates is useful in assessing the optimum environmental conditions in which to nurse them $(4,6-8,18)$, and in making calculations of their energy expenditure, which, in conjunction with nutritional balances, can be used to determine the composition of their growth $(3,5,12,13,15)$. Many different techniques have been used to study respiratory metabolism $(2,9-11,14,16,17,19-21,23)$ but all have the dual drawbacks of disturbing the infant's normal environment and of being limited to a maximum period of only a few hours. If such measurements are to be used to their best advantage, they must accurately reflect the infant's $\dot{\mathrm{VO}}_{2}$ over much longer periods and in his normal environment. It is not at all certain that they do. We have recently developed a method

Received July 5, 1983; accepted February 7, 1984.

Requests for reprints may be addressed to Dr. O. G. Brooke, Department of Child Health, St George's Hospital, London, SW 17 ORE, United Kingdom.

Y. M. A. is supported by a grant from the Ministry of Education, United Arab Emirates. for measuring $\dot{\mathrm{V}}_{2}$ over prolonged periods in a normal nursing incubator (1) and this paper examines the differences between these prolonged measurements and measurements made over shorter periods of time.

\section{MATERIALS AND METHODS}

The method for $\dot{\mathrm{V}}_{2}$ measurement has been described previously (1). The principle is that a normal nursing incubator acts as a metabolic chamber for open circuit indirect calorimetry. The incubator used is a Vickers 79 (Vickers Medical Ltd, Basingstoke, England) but any incubator with good internal air circulation could probably be substituted. Access holes are sealed during the measurement period and under these conditions a slight negative pressure can be generated within the canopy by extracting air through a large bore tube at a sufficient rate $(\sim 12$ liters/min). This ensures that all expired air is removed for respiratory gas measurements. A large stable pump and accurate flow measurements are essential. Mixed expired air is sampled automatically by a solenoid-operated cycling device and is compared with reference air (room air) in alternating 2-min cycles. Oxygen concentration is measured with a paramagnetic analyzer (Taylor Servomex, Crowborough, England) and continuous comparisons are made between the concentration in reference air and mixed expired air by an integrating computer. The sensitivity of the Servomex analyzer is $1 \%$ of full scale deflection. Using zero suppression and suitable electrical amplification, full scale deflection can be adjusted to the range $0-0.5 \%$ of oxygen. In this range, sensitivity of $5 \times 10^{-3} \%$ can be achieved. $\mathrm{VO}_{2}$ is then calculated in the usual way, from the measured reduction in $\mathrm{O}_{2}$ concentration in the mixed expired air and the rate of extraction of air from the incubator. Metabolic rate is derived from the $\dot{\mathrm{VO}}_{2}$ measurements, the RQ being determined from simultaneous $\mathrm{CO}_{2}$ determinations if available, or assumed to be 0.9 .

The system was calibrated by burning butane at physiological rates of $\mathrm{O}_{2}$ consumption. Calibrations for the studies are shown in Table 1. Mean error was $4.3 \%$. Maximum measured error was $6.8 \%$. As would be expected, the error was always negative with respect to the absolute measured rate of $\mathrm{O}_{2}$ consumption (assessed by the weight of gas burned). This probably reflects a 
small amount of residual leakage and cannot be improved upon. We have established that the internal air circulation of the Vickers 79 incubator is excellent and no errors were introduced by sampling from different quarters of the canopy, though in practice we sampled from a central hole in the top surface. The measurements did not disturb the thermal stability of the incubator.

During this time, the infants were handled as little as possible, and feeding was carried out via an extension of the nasogastric tube which was brought out through an access hole in the canopy. The ports were opened every $4 \mathrm{~h}$ for diaper changes and other attention, and the effect of these periods was always obvious on the recorded traces of the $\mathrm{O}_{2}$ concentration measurements. The time to regain stable readings after closure of the ports was between 5 and $15 \mathrm{~min}$, depending on the length of time the ports were left open, so a maximum of $1 \frac{1 / 2}{h}$ of measurement was lost during each 24-h period. Observations on the infant's behavior and on any procedures done were recorded at the appropriate time on the $\mathrm{O}_{2}$ measurement trace by the nurse in charge of the infant. Fig. 1 shows the effect of opening the incubator ports on the respiratory gas record (in this case including $\mathrm{CO}_{2}$ measurement).

Subjects. The data presented here were obtained from measurements made on 18 preterm infants: birthweight, $900-2560 \mathrm{~g}$. Mean weight at time of measurement was $1584 \mathrm{~g}$ (range, 985$2510 \mathrm{~g}$ ). Six infants were small for gestational age. At the time of study, all infants were on full enteral (nasogastric tube) feeding,

Table 1. Calibrations obtained during the studies by burning butane

\begin{tabular}{cccc}
\hline $\begin{array}{c}\text { Weight of butane } \\
\text { burned }(\mathrm{g})\end{array}$ & $\begin{array}{c}\text { Calculated } \\
\dot{\mathrm{V}}_{2}(\mathrm{ml} / \mathrm{min})\end{array}$ & $\begin{array}{c}\text { Measured } \\
\dot{\mathrm{V}}_{2}(\mathrm{ml} / \mathrm{min})\end{array}$ & \% Error \\
\hline 0.62 & 31.12 & 30.05 & 3.4 \\
2.12 & 24.19 & 22.57 & 6.8 \\
2.80 & 25.10 & 24.89 & 0.8 \\
1.13 & 12.59 & 11.82 & 5.9 \\
0.65 & 13.62 & 13.21 & 3.0 \\
0.97 & 17.35 & 16.25 & 6.3 \\
2.80 & 15.55 & 15.18 & 2.4 \\
1.95 & 17.31 & 16.57 & 4.9 \\
1.09 & 16.99 & 16.04 & 5.6 \\
\hline
\end{tabular}

receiving 120-190 $\mathrm{kcal} / \mathrm{kg}$.day. Postnatal age at the time of study ranged from 4 to 46 days. The infants were nursed in what was considered to be a thermoneutral environment (7). In 16 of the 18 infants, the ME was determined. This was done by subtracting fecal and urinary energy losses from the energy intake. The energy density of the feed was measured by ballistic bomb calorimetry and the intake was determined by careful measurements of feed volume consumed. Urine and stools were collected separately, freeze dried, and analyzed for energy content by bomb calorimetry. The methods have been described previously (3).

Parental consent for the studies was obtained in all cases and the mothers were usually present during part of the measurement period. The study had ethical approval.

\section{RESULTS}

Table 2 gives the 24-h $\dot{\mathrm{V}}_{2}$ and derived metabolic rate in all 18 infants, with birthweight, gestational and postnatal age, energy intake, and metabolizable energy at the time of study. Mean $\dot{\mathrm{V}}_{2}$ was $9.66 \pm 1.25$ liters $/ \mathrm{kg} \cdot 24 \mathrm{~h}(\mathrm{SD})$, or $6.71 \mathrm{ml} / \mathrm{kg} \cdot \mathrm{min}$, in normally grown infants and $10.09 \pm 1.21$ liters $/ \mathrm{kg} \cdot 24 \mathrm{~h}(7.00$ $\mathrm{ml} / \mathrm{kg} \cdot \mathrm{min})$ in small for gestation infants. These differences were not significant. Twenty-four-hour $\dot{\mathrm{VO}}_{2}$ was highly correlated with body weight $(r=+0.87)$ and with $\mathrm{ME}(r=+0.77)$ but not at all with birth weight, postconceptional age, or postnatal age.

The 3-h period having the lowest and the highest $\mathrm{VO}_{2}$ during the 24-h measurement was selected in each infant. These values are given in Table 3 . There was a significant difference in the $\mathrm{V}_{2}$ measurements during these periods using the paired $t$ test ( $p$ $<0.001$ ). On average, the highest $\mathrm{V}_{2} / 3 \mathrm{~h}$ was $13.8 \%$ above the 24-h -mean, and the lowest $\mathrm{VO}_{2} / 3 \mathrm{~h}$ was $12.6 \%$ below the $24-\mathrm{h}$ mean.

Although we had no means of measuring activity levels reliably, periods of high $\dot{\mathrm{V}}_{2}$ were often associated with increased physical activity, as observed and recorded by the investigator or the nurse in charge, or were found after the infant had been handled. In general, the difference between the highest and lowest 3-h measurement periods were not accounted for by variations in feeding or milk intake (most infants were receiving continuous feeds) and we did not detect a circadian rhythm of $\dot{\mathrm{VO}}_{2}$. The variability in energy expenditure appeared to be greater in the

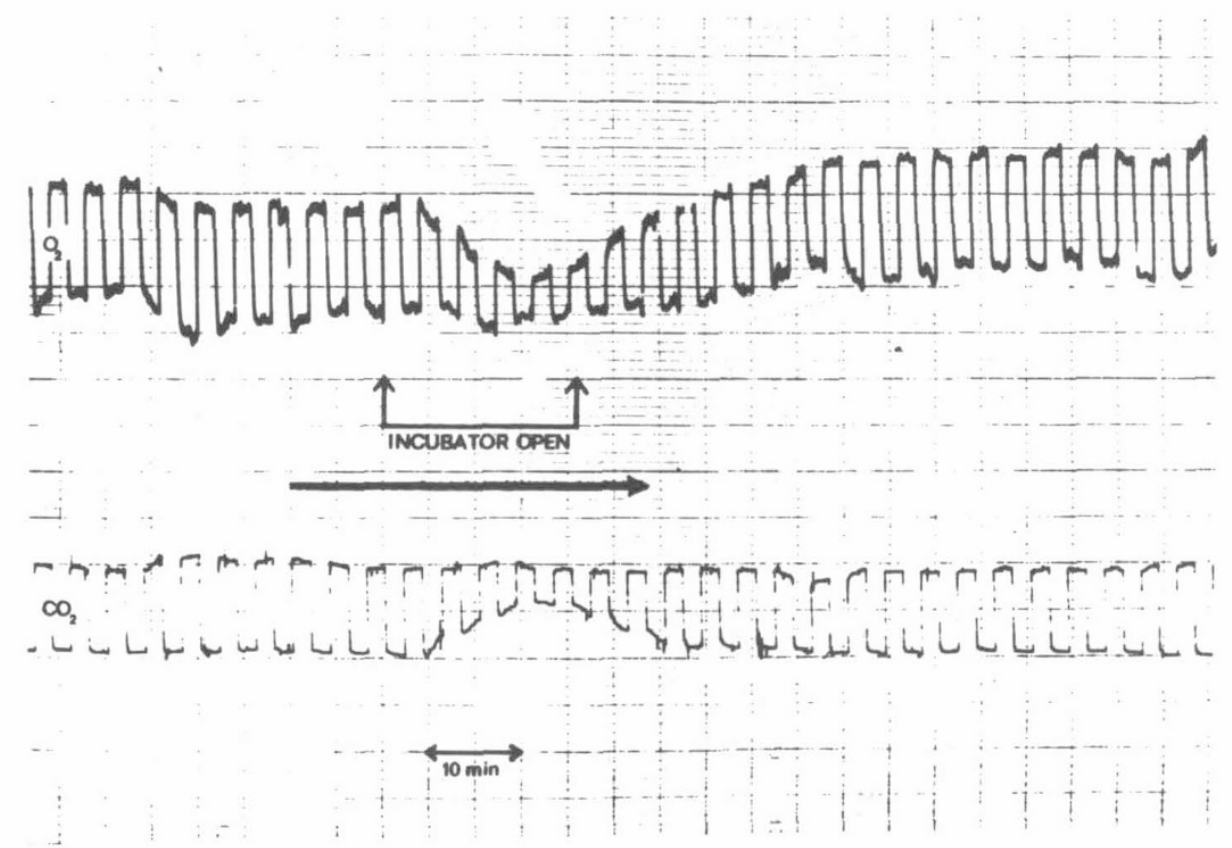

Fig. 1. A section of the recording of continuous $\mathrm{V}_{2}$ and $\mathrm{CO}_{2}$ production (infant $\mathrm{K}$. J.), showing the effect of opening the incubator ports to attend to the infant. 
Table 2. Data on oxygen consumption and metabolic rate in 18 preterm infants

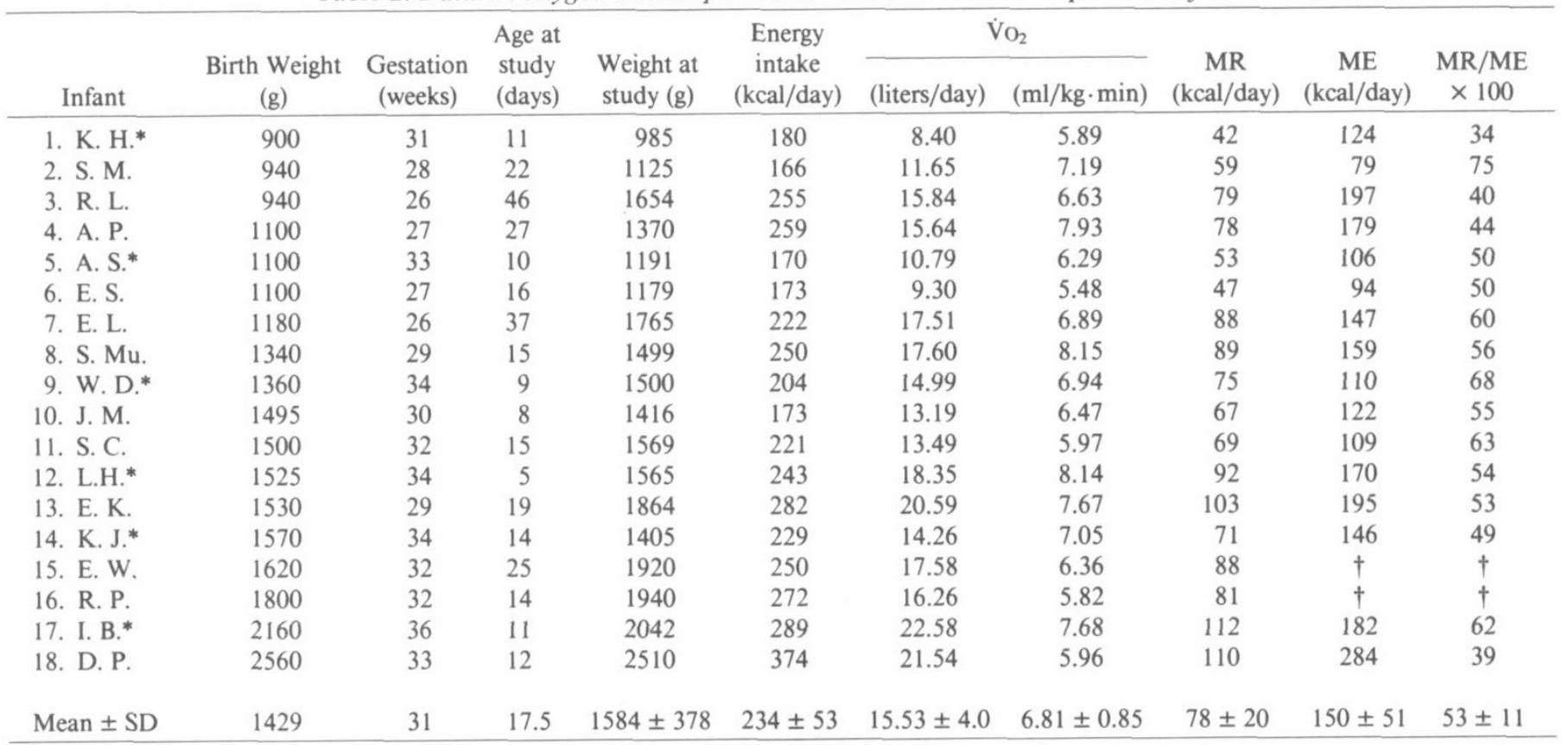

* Small for gestational age.

$\dagger$ Not measured.

Table 3. Highest and lowest $\mathrm{VO}_{2}$ during 3 consecutive $h$ in each 24-h measurement period

\begin{tabular}{|c|c|c|c|}
\hline Infant & $\begin{array}{c}\text { Highest } \dot{\mathrm{VO}}_{2} / 3 \mathrm{~h} \\
(\mathrm{ml} / \mathrm{kg} \cdot \mathrm{min})\end{array}$ & $\begin{array}{c}\text { Lowest } \dot{\mathrm{V}}_{2} / 3 \mathrm{~h} \\
(\mathrm{ml} / \mathrm{kg} \cdot \mathrm{min})\end{array}$ & $\Delta$ \\
\hline K. H. & 6.28 & 4.97 & 1.31 \\
\hline S. M. & 8.05 & 6.92 & 1.13 \\
\hline R. L. & 8.03 & 5.77 & 2.26 \\
\hline A. P. & 8.58 & 7.21 & 1.37 \\
\hline A. $S$. & 6.55 & 4.51 & 2.04 \\
\hline E. S. & 6.81 & 5.21 & 1.60 \\
\hline E. L. & 7.22 & 6.56 & 0.66 \\
\hline S. Mu. & 8.31 & 7.41 & 0.90 \\
\hline W. D. & 8.43 & 5.40 & 3.03 \\
\hline J. M. & 7.39 & 5.08 & 2.31 \\
\hline S. C. & 6.79 & 5.33 & 1.16 \\
\hline L. H. & 8.52 & 7.07 & 1.45 \\
\hline E. K. & 8.52 & 6.88 & 1.64 \\
\hline K. J. & 9.01 & 6.70 & 2.31 \\
\hline E.W. & 7.21 & 5.63 & 1.58 \\
\hline R. P. & 7.45 & 5.28 & 2.17 \\
\hline I. B. & 9.34 & 6.27 & 3.07 \\
\hline D. P. & 7.06 & 4.98 & 2.08 \\
\hline Mean \pm SD & $7.75 \pm 0.89$ & $5.95 \pm 0.92$ & $1.78 \pm 0.68$ \\
\hline
\end{tabular}

small for gestation infants but the differences were not statistically significant.

\section{DISCUSSION}

The technique used here allows measurement of $\mathrm{V}_{2}$ to be made while the infants are nursed in their normal neonatal nursery environment. It should therefore reflect daily routines and their influence on the infant's metabolism better than the older techniques which have been described. The use of a head canopy within the incubator $(3,12)$ comes closest to fulfilling these aims and allows measurements to continue while the infants are handled, but the canopy will itself influence the thermal environment of the infant's head and thus may affect oxygen consumption (22). It is an obvious disadvantage of our technique that the measurements cannot be made while the infant is actually being handled. However, as Figure 1 shows, it is clear when measurement stability is restored, and the advantages of many hours of uninterrupted measurement probably outweighs the small loss of information entailed.

The mean 24-h oxygen consumption rate of the infants in our study is similar to values obtained by others over shorter periods of measurement, and some of the reported values are compared in Table 4. Detailed comparisons are not relevant here since we have not attempted to standardize postnatal age or energy intake in these studies, but on the face of it, it would appear that short term measurements are a reasonably satisfactory approximation of values obtained while the infants are said to be in a state of minimal activity. Such values, being similar to those which we have obtained over a whole 24-h period, including all muscular and postprandial energy expenditure, may therefore be an overestimate of the resting energy expenditure. Of the measurements cited in Table 3, only those of Senterre and Karlberg (17) and Mestyân et al. (11) were lower than the values found in our lowest periods of measurement (Table 2), and the values obtained by Reichman et al. (12) over $6 \mathrm{~h}$ were considerably higher than our mean 24-h value, perhaps because the metabolizable energy intake in their infants was greater. It is evident that there is considerable scope for error in assuming that short term measurements can be representative either of minimal resting metabolism or of energy expenditure over prolonged periods. Short

Table 4. Comparison of length of $\mathrm{V}_{2}$ measurement and the values obtained in various published studies

\begin{tabular}{ccllc}
\hline Reference & $\begin{array}{c}\text { No. of } \\
\text { infants }\end{array}$ & $\begin{array}{c}\text { Age at } \\
\text { study }\end{array}$ & $\begin{array}{c}\text { Length of } \\
\text { measurement }\end{array}$ & $\begin{array}{c}\dot{\mathrm{VO}}_{2} \\
(\mathrm{ml} / \mathrm{kg} \cdot \mathrm{min})\end{array}$ \\
\hline 14 & 43 & $1-2$ weeks & $3-15 \mathrm{~min}$ & 8.3 \\
17 & 14 & 1st week & $3 \mathrm{~h}$ & 5.4 \\
3 & 15 & 2 weeks & $5-10 \mathrm{~min}$ & 6.5 \\
20 & 135 & 1-53 days & $15 \mathrm{~min}$ & 7.2 \\
14 & 36 & 17-18 days & Not stated & 5.8 \\
12 & 13 & 8-43 days & 6 h & 8.7 \\
16 & 11 & 14-20 days & Not stated & 6.8 \\
\hline
\end{tabular}


periods of measurement under carefully controlled conditions can certainly provide information about maintenance requirements, but if data are required on which to base decisions about the thermal environment, or to calculate energy balance, then it seems that long periods of measurement are essential. From our data, we concur with Reichman et al. that at least $6 \mathrm{~h}$ are required.

Assuming that the lowest values of $\dot{\mathrm{V}}_{2}$ recorded during our 24-h measurement periods represented something approaching the resting metabolism (resting metabolic rate), it is possible to draw some conclusions about the energy cost of activity. Quite high values of $\dot{\mathrm{V}}_{2}$ were seen during short bursts of intense activity and crying but the variation between our lowest and average highest periods probably represents the changes due to differing degrees of alertness and vigilance. As would be expected, this variation was least in the smallest and most immature infants, but the $32 \%$ difference which was found between the mean value for resting metabolic rate and the periods of greatest energy expenditure is in good agreement with the value of 32 $40 \%$ given by Stabell et al. (20) in their studies of neonatal energy expenditure during different states of activity.

Prolonged measurements of energy expenditure are particularly important in metabolic balance studies. If calculations of the energy cost of growth and changes in body composition during growth are to be made by balance techniques $(3,5,12$, $13,15)$, an accurate determination of the proportion of the energy intake which is oxidized is vital, since calculations of stored energy depend on this figure as much as they do on the accurate measurement of energy intake and losses in the excreta. Our data show that about $53 \%$ of the metabolizable energy intake was oxidized during the measurements periods. This is similar to the figure of $48 \%$ in Reichman's studies (13) using 6-h measurements, even though the ME in Reichman's infants was considerably higher. There is, however, a great deal of variation in this quantity, ranging from $34 \%$ in the smallest infant up to $75 \%$. We found no correlation between the oxidized portion of the $\mathrm{ME}$ and postnatal age, birth weight, or gestational and postconceptional age. The efficiency of metabolism in these small infants is greatly variable and probably accounts for their widely differing growth rates. Intestinal malabsorption is an important contributor to this variation in metabolic efficiency since there are large differences between individuals in the ratio between metabolizable energy and energy intake. It is difficult therefore to provide firm recommendations for their energy intake.

\section{REFERENCES}

1. Abdulrazzaq Y, Brooke OG, De Benois B, Depla P 1983 A method for measuring metabolic rate by open circuit indirect calorimetry over prolonged periods in neonates. J Physiol (Lond) 340:4P

2. Bhakoo NN, Scopes JW 1974 Minimal rates of oxygen consumption in small for date babies during first week of life. Arch Dis Child 49:583

3. Brooke OG, Alvear J, Arnold M 1979 Energy retention, energy expenditure and growth in healthy immature infants. Pediatr Res 13:215

4. Brück K, Parmelee AH, Brück M 1962 Neutral temperature range and range of "thermal comfort" in premature infants. Biol Neonate 4:32

5. Gudinchet F, Schutz Y, Micheli JL, Stettler E, Jequier F 1982 Metabolic cost of growth in very low-birth-weight infants. Pediatr Res 16:1025

6. Hey EN 1969 The relation between environmental temperature and oxygen consumption in newborn baby. J Physiol (Lond) 200:589

7. Hey EN 1971 The care of babies in incubators. In: Gairdner D, Hull D (eds) Recent Advances in Paediatrics, 4th ed. Churchill, London, p 177

8. Hey EN, Katz G 1970 The optimum thermal environment for naked babies. Arch Dis Child 45:328

9. Hill JR, Robinson DC 1968 Oxygen consumption in normally grown, small for dates and large for dates newborn infants. J Physiol (Lond) 199:683

10. Lister G, Hoffman JJE, Rudolph A 1974 Oxygen uptake in infants and children: a simple method for measurement. Pediatrics 53:656

11. Mestyán J, Fekete M, Bata G, Jarái I 1964 The basal metabolic rate of premature infants. Biol Neonate 7:11

12. Reichman B, Chessex P, Putet G, Verellen G, Smith JM, Heim T, Swyer P 1981 Diet, fat accretion, and growth in premature infants. N Engl J Med 305:1495

13. Reichman B, Chessex P, Putet G, Verellen G, Smith JM, Heim T, Swyer P 1982 Partition of energy metabolism and energy cost of growth in the very low-birth-weight infant. Pediatrics 69:446

14. Rutter N, Brown SM, Hull D 1978 Variations in the resting oxygen consumption of small babies. Arch Dis Child 53:850

15. Sauer PJ, Pearse RG, Dane HH, Visser HKA 1979 The energy cost of growth estimated from simultaneous direct and indirect calorimetry in infants of less than $2500 \mathrm{~g}$. In: Visser HKA (ed) Nutrition and Metabolism of the Fetus and Infant. Martinus Nijhoff, The Hague, $\mathrm{p} 93$

16. Scopes JW, Ahmed I 1966 Minimal rates of oxygen consumption in sick and premature newborn infants. Arch Dis Child 41:407

17. Senterre J, Karlberg P 1970 Respiratory quotient and metabolic rate in normal full-term and small-for-date newborn infants. Acta Paediatr Scand 59:653

18. Silverman WA, Sinclair JC, Agate FJ 1966 Oxygen costs of minor changes in heat balance of small newborn infants. Acta Paediatr Scand 55:294

19. Smales C 1978 Simple method for measuring oxygen consumption in babies. Arch Dis Child 53:53

20. Stabell U, Junge M, Fenner A 1977 Metabolic rate and oxygen consumption in newborns during different states of vigilance. Biol Neonate 31:27

21. Stern L, Lees MH, Ledne J 1965 Environmental temperature, oxygen consumption, and catecholamine excretion in newborn infants. Paediatrics $36: 367$

22. Stothers J 1981 Head insulation and heat loss in the newborn. Arch Dis Child 56:530

23. Thompson J, Brice JEH, Kurdy NMG, Walker CHM 1979 A modified open circuit method for estimation of oxygen consumption and carbon dioxide excretion in adults, infants and small animals. Pflugers Arch 380:197 